\title{
"OFF CAMPUS TRAINING IN BULGARIAN LANGUAGE AND SPORT" AS A WAY FOR SOCIALIZATION AND FORMATION OF COMMUNITY
}

\author{
A. Bozhkova*, V. Ivanov, P. Slavcheva-Hinkova \\ Department of Language Education and Sport (DLES), Sport Sector, Medical University - Sofia, \\ Sofia, Bulgaria
}

\begin{abstract}
The off-campus education in Bulgarian language and Sports is part of the preparatory school year of international students wishing to study in the medical specialties of Medical University - Sofia. The program includes Bulgarian classes, winter sports - skiing and hiking, and table tennis. The event is attended by current students from the Medical University of Sofia, which contributes to the socialization of international students and community formation.

The primary method of work is an anonymous survey with six questions that require specific answers. It covers various essential questions about the students' sport - recreational knowledge and needs, which will provide guidance for improving the organization and program content of the training delivered. It was held after the completion of the Bulgarian language and sports training in the town of Bansko in the period from $02-09.02 .2019$.

We have set the following tasks:

1) to study the students' opinion on the main objectives of the off-campus training, on sporting events, and

2) to draw conclusions and recommendations for the future implementation and optimization of the off-campus training.

The following conclusions were made:

1. After successfully completing the initial ski and hiking training of students, most of them appreciate the benefits of outdoor activities as beneficial to health and as accessible to future independent activities.

2. The off-campus training organized for Bulgarian and an international student creates good conditions for socialization and building a more cohesive community.

3. Through such events, lecturers acquire greater organizational experience in working with students and optimizing their sessions.
\end{abstract}

Key words: survey, Bulgarian language education, student community, winter sports, socialization, outdoor activities, recreation, external training.

\section{INTRODUCTION}

The Department of Language Learning and Sports (DEOS) organizes and conducts an eight-month preparatory course for Bulgarian language for international students, future students of the Medical University of Sofia. As part of it is also the off campus training in Bulgarian language and sport and socialization. The training for international students is

\footnotetext{
*Correspondence to: Anna Bozhkova, Department of language education and sport (DLES), Sport sector, Medical University - Sofia, Sofia, Bulgaria, E-mail: abozhkova@abv.bg,Tel: +359888309890;
}

conducted in Bansko by combining and alternating Bulgarian language classes with winter sports such as skiing, hiking and table tennis. It also includes Bulgarian students from the Medical University - Sofia, who participate with international students in sports activities. In our previous publications, the curriculum is presented (1, 5), and the peculiarities, realization, and attitude of the students to the sports lessons included in the exported training were studied $(1,2)$. In a study carried out by Albert M. \& E. Albert (9), 87.62\% of the students surveyed at the Medical College at the Medical University in Sofia stated that their 
sports activities create favorable conditions for meeting new people and social contacts.

The Bulgarian language education of international students, combined with sports activities together with Bulgarian students, is a modern approach in the delivered training. This stage of socialization enables them to form a community. The dynamic change in the nationality, age and sex of the students who choose to study at the Medical University Sofia, requires teachers to actively improve the curriculum "Extracted Bulgarian Language and Sport" on the content, the conditions and the means used in it $(3,4,6,7)$.

This study aims to evaluate the attitude of international students on the sports activities included in the program and the impact they have on improving their psycho-physical training during the socialization course in the future.

BOZHKOVA A., et al.

The survey covers various and essential questions about the students' sport recreational knowledge and needs, which provide guidance for improving the organization and programming content of the training delivered.

The tasks to be solved are as follows:

1. Explore the students' views on the main goals of the training delivered.

2. Draw conclusions and recommendations for the future conduct and optimization of training.

\section{MATERIALS AND METHODS}

The main method of work is the survey. It is anonymous and contains 6 questions that require specific answers (Appendix 1). It was held at the end of the Bulgarian language and sports training in Bansko from 02 - 09.02.2019 The subject of the study is 24 foreign students from Germany, Greece, Lebanon, Syria and Turkey (Figure 1), of these, 13 men and 11 women. The average age of the students is 18.6 years.

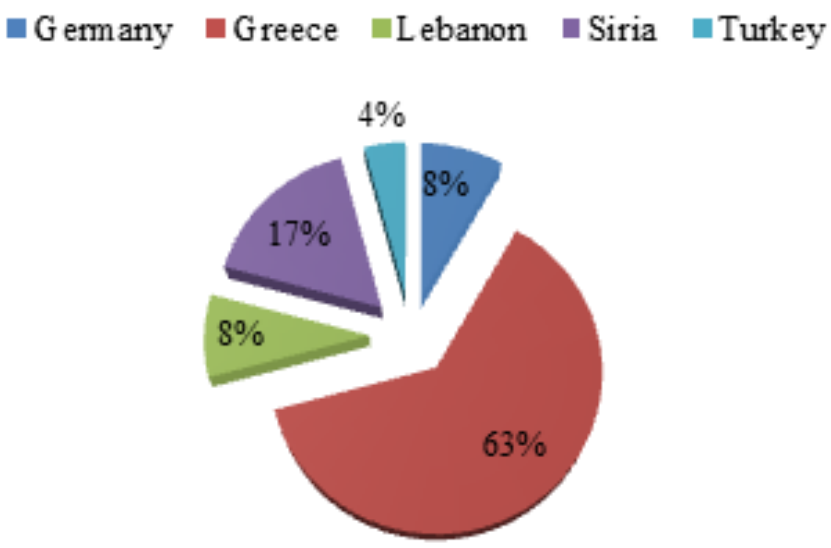

Figure 1. Nationality of the students

An alternative analysis is used to process the data, which represents the percentage values.

\section{DISCUSSION}

The students that practiced (46\%) and did not practice winter sports (42\%) is almost equal, which is somewhat understandable due to the geographical situation of the countries of which the students are, while the rest (12\%) participated in mountain tourism 2). Taking into account the more accessible activity, such as mountain tourism, our task is to persuade students to practice it systematically for the purpose of recreation.
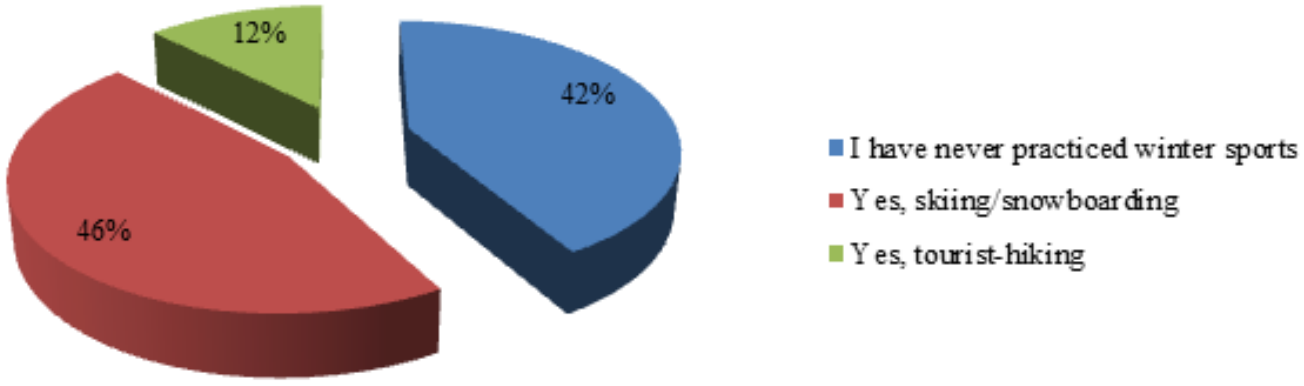

Figure 2. Have you practiced winter sports? 
In comparison with our previous study (2), in which $83 \%$ responded positively to the issue of the beneficial and calming effect of outdoors natural factors, in this case, there is a lower percentage of $71 \%$. Again, the answer is "somewhat" in a small portion of the students -

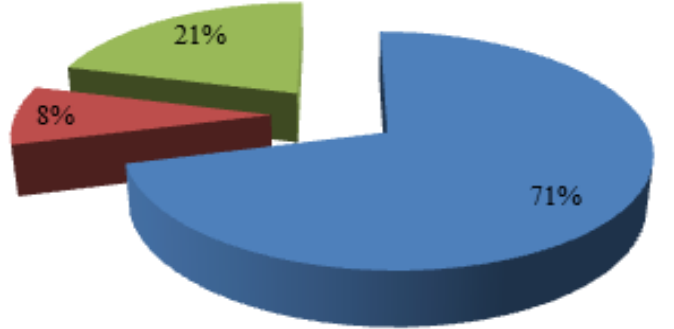

BOZHKOVA A., et al. $21 \%$, even $8 \%$ (Figure 3). Here is the role of the lecturer to acquaint students with: 1) the positive outcome of outdoor activities, and

2) that practicing outdoor sports further enhances the effect of physical exercise.

Figure 3. Are you aware of the beneficial and calming effect of outdoors natural factors (fresh air, sun, altitude) on the body?

In Figure 4 shows that an equal percentage of students responded with "very good" and "good influence me" (46\%) on the question "How do you assess the impact of winter sports on improving your overall physical training and the degree of development of motor skills?". The high rate for both
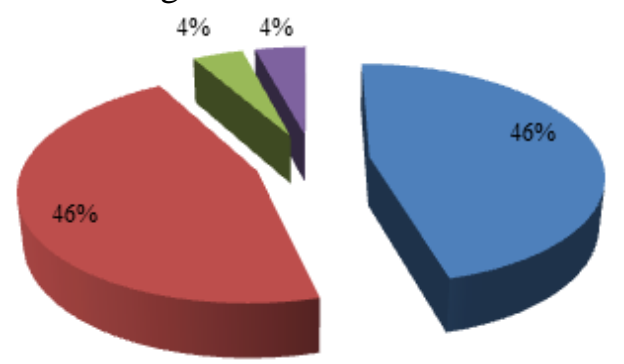

responses is a good indicator that the younger generation can assess the effect of practicing winter sports. The percentage of practitioners $(4 \%)$ is minimal and equal, which cannotjudge the impact of the activities and those that do not affect them well (Figure 4).

Figure 4. How do you assess the impact of winter sports on improving your overall physical training and the degree of development of motor skills?

In Figure 5 presents the opinion of the students about the sports activities included in the external training - ski and tourism. For $58 \%$, occupations have a positive impact on

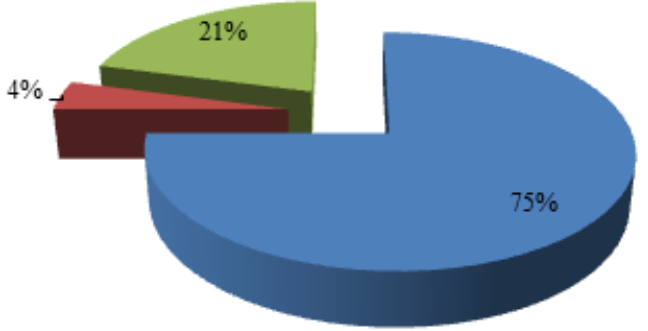

their health, $29 \%$ are unloaded while practicing skiing and tourism, and a small proportion of students find that these sports enrich their sports culture.

Figure 5. What do you think about sports activities - skiing and hiking included in the training?

From Figure 6 shows that a significant proportion of students $(75 \%)$ appreciate the benefits of outdoor sports by helping their psycho-physical recovery. A total of $25 \%$ think that they do not feel the positive impact at all or not at all.
Along with winter sports, other types of outdoor sports can also be practiced. I. Peltekova (8) shows, for example, that streetball play can help to combat the "sedentary" lifestyle of young people and to achieve a higher level of communication among young people. In this way, the curricula are enriched with useful sports. 


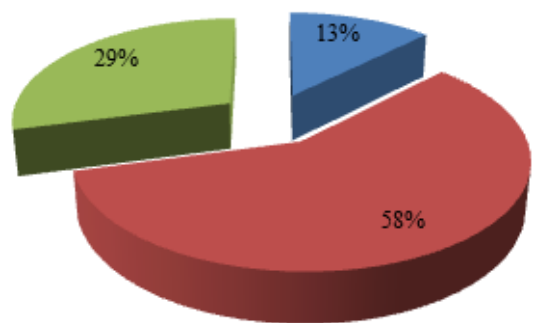

" enrich my sport's culture

improve my health status

an otionally unl oading me

Figure 6. Does outdoor sport help your psycho-physical recovery?

After the off campus winter sports training with the students, they have the opportunity to evaluate the teachers on the quality of the training. Significantly prevailing estimates are "Excellent" and "Very good" (87\% overall)
(Figure 7). The conclusion is that the trainers are doing well with their duties related to observing the pre-program for the training, the teaching methodology, and the organization.
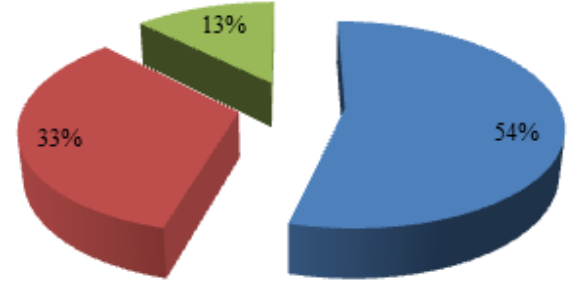

" ex cellent
- very good
" good

Figure 7. What is your assessment of the lecturers who have conducted the winter sports training?

\section{CONCLUSIONS}

The conclusions that can be drawn are as follows:

1. After successfully completing the initial ski and hiking training of students, most of them appreciate the benefits of outdoor activities as beneficial to health and as accessible to future independent activities.

2. Organizing excursions organized for Bulgarian and international students create good conditions for socialization and building a more cohesive community.

3. Through such events, lecturers acquire greater organizational experience in working with international students and optimizing their sessions.

\section{REFERENCES}

1. Bozhkova, A. Realization and peculiarities of the sports lessons included in the Bulgarian language and sports training of the students from the eight-month preparatory course of DEOSS at the Medical University - Sofia. Yearbook, MU - Sofia, DEOSS, item II, pp. 37-41, ISSN 1313-9606, S., 2011.

2. Bozhkova, A. Studying the attitude of the students from the preparatory course of DEOSS at the Medical University - Sofia to the sports activities included in the excursion of Bulgarian language and sport. Yearbook, MU - Sofia, DEOSS, item II, pp. 42-50, ISSN 1313-9606, S., 2011.
3. Dyakova, G., M. Sinilkova, M. Popova, P. Petkov. Physical education manual (for organized and stand-alone exercises). ISBN 978-954-338-031-2, Ac. ed. Trakia University, Stara Zagora, 2012.

4. Dyakova, G. A textbook on physical education and sport. Ac. ed. Trakia University, Stara Zagora, ISBN 978-954-338-046-6, 2013.

5. Ivanov, V. Ski - a guide for students. ISBN978-954-796-060-2, Sofia, Polis Publishing House, 2016.

6. Ivanov, V. Theory and methods of physical education - a guide for kinesitherapists. ISBN ISBN978-954-796-061-9, Polis Publishing House, Sofia, 2016.

7. Ivanov, V. Curriculum for the advanced training of the students from the Faculty of Dental Medicine and foreign students at the Medical University - Sofia in tennis, table tennis and skiing. Annual, MU - Sofia, CEOFVS, item III, pp. 95-101, ISSN 13139606, S., 2016.

8. Peltekova, I. Streetball - outdoor sport in leisure time. A scientific conference dedicated to 80 years of sport in Alma Mater, "Optimization and Innovation in the Training Process". ISBN 978-954-07-2987-9, S., IM: "St. KlimentOhridski ", pp. 136-146, 2009.

9. Albert M., E. Albert. Optimization of teaching methods in sports classes in students with visual impairments. Journal of Applied Sports Sciences, Vol. 1, pp. 63-77, ISSN 2534-9597 (Print), ISSN 2535-0145 (Online), 2017. 


\section{Questionnaire}

Dear students,

The present study aims to establish your attitude towards the sports activities, included in the external winter sports' training.

You can choose more than one answer.

Sex: $F \quad M \quad$ Age:

Country:

1. Have you practiced winter sports until now?

yes, skiing/snowboarding

yes, tourist-hiking

I have never practiced winter sports

2. Are you aware of the beneficial influence and the seasoning effect of the natural factors (fresh air, sun, altitude) on the body?

$$
\begin{aligned}
& \text { yes, I am familiar with them } \\
& \text { no } \\
& \text { somewhat }
\end{aligned}
$$

3. How do you assess the impact of the winter sports on improving your overall physical training and the degree of development of the motor skills?

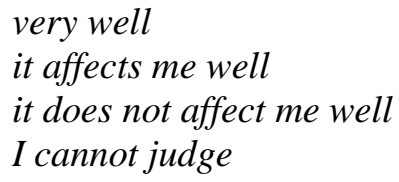

4. What do you think about the sports activities included in the external training - skiing and hiking?

enrich my sport's culture

improve my health status

emotionally unloading me

5. Does the outdoor sport help your psycho-physical recovery?

$$
\begin{aligned}
& \text { yes } \\
& \text { no } \\
& \text { somewhat }
\end{aligned}
$$

6. What is your assessment of the lecturers who carried out the external winter sports' training?

$$
\begin{aligned}
& \text { excellent } \\
& \text { very good } \\
& \text { good } \\
& \text { poor }
\end{aligned}
$$

